\title{
BMJ Open Retrospective observational study of temporal trends and outcomes of hepatitis B screening in patients receiving rituximab
}

\author{
Mahnur Haider (D) , ${ }^{1}$ Gianina Flocco, ${ }^{2}$ Rocio Lopez, ${ }^{3}$ William Carey ${ }^{2}$
}

To cite: Haider M, Flocco G, Lopez R, et al. Retrospective observational study of temporal trends and outcomes of hepatitis B screening in patients receiving rituximab. BMJ Open 2020;10:e043672. doi:10.1136/ bmjopen-2020-043672

- Prepublication history for this paper is available online. To view these files, please visit the journal online (http://dx.doi. org/10.1136/bmjopen-2020043672).

Received 10 August 2020 Revised 10 November 2020 Accepted 23 November 2020

Check for updates

(c) Author(s) (or their employer(s)) 2020. Re-use permitted under CC BY-NC. No commercial re-use. See rights and permissions. Published by BMJ.

${ }^{1}$ General Internal Medicine and Geriatrics, Tulane University, New Orleans, Louisiana, USA ${ }^{2}$ Gastroenterology and Hepatology, Cleveland Clinic, Cleveland, Ohio, USA

${ }^{3}$ Quantitative Health Sciences, Cleveland Clinic, Cleveland, Ohio, USA

Correspondence to

Dr Mahnur Haider;

mahnurhaider@gmail.com

\section{ABSTRACT}

Objective Hepatitis $B$ reactivation $(\mathrm{HBr})$ is strongly associated with rituximab therapy. Guidelines advise hepatitis $B$ screening and use of preventive nucleoside analogue (NA) in patients at risk. In this study, we examined screening trends, post-screening interventions and outcomes in patients receiving rituximab in light of recommendations.

Design Retrospective, observational study.

Setting Single, tertiary care centre in the USA.

Participants Patients receiving rituximab from January 2005 to December 2017.

Primary outcome Trends of hepatitis B screening prior to initiation of rituximab.

Secondary outcome Results of hepatitis B screening, use of preventive NA therapy and $\mathrm{HBr}$ incidence.

Results Over 13 years, 2219 patients received rituximab. Screening, with at least hepatitis B core antibody (anti$\mathrm{HBc}$ ) prior to the first dose of rituximab, improved from $20 \%$ to $97 \%$. Because only $4.5 \%$ of patients had a positive anti- $\mathrm{HBc}$, the overall $\mathrm{HBr}$ incidence was very low $(0.42 \%)$. In susceptible patients, the incidence of $\mathrm{HBr}$ was $8 \%$. In at-risk patients given preventive NA, 96\% remained free of $\mathrm{HBr}$. However, only $23 \%$ received a preventive NA and no temporal improvement in compliance was seen. Of those with $\mathrm{HBr}, 87.5 \%$ were hepatitis $\mathrm{B}$ surface antigen ( $\mathrm{HbsAg-}$ )/anti-HBc+.

Conclusions In those treated with rituximab, we demonstrated near-universal anti-HBc screening. Screening unlinked to preventive NA use, in those who are anti- $\mathrm{HBC}+$, is ineffective in reducing $\mathrm{HBr}$. $\mathrm{HBr}$ has a high fatality rate. The majority of cases occurred in those who were HBsAg negative. Efforts are needed to educate providers who use rituximab not only to screen for anti-HBc, but to provide preventive NA to those who test positive.

\section{INTRODUCTION}

Rituximab therapy poses six times higher odds of hepatitis $\mathrm{B}$ reactivation $(\mathrm{HBr})$ compared with chemotherapy regimens that do not contain rituximab in susceptible individuals. ${ }^{1}$ The estimated risk of $\mathrm{HBr}$, with rituximab therapy, in patients with hepatitis B surface antigen (HBsAg) positive is $30 \%-60 \%$ and in patients with HBsAg negative and hepatitis $\mathrm{B}$
Strengths and limitations of this study

- Large, retrospective study evaluating the trends of screening over more than a decade.

- Observational data on real-life practices and effect of screening.

- Limited generalisability as this was a single-centre study.

- Unable to assess perceptions or reasons for screening trends.

core antibody (anti-HBc) positive is greater than $10 \% .^{2}$ With the use of a nucleoside analogue (NA), $\mathrm{HBr}$ can be prevented by $79 \%-100 \%{ }^{3}$ The NAs, entecavir and tenofovir are considered superior to lamivudine since they are more potent and have lower rates of resistance. ${ }^{34}$

In 2008, the Center for Disease Control and Prevention (CDC) recommended screening for hepatitis B in patients undergoing treatment with rituximab and in 2013 the Federal Drug Administration (FDA) issued a black box warning to screen for hepatitis B before initial treatment and to monitor for symptoms during and after treatment. ${ }^{156}$ Over the last decade, the recommendations regarding $\mathrm{HBr}$ in patients receiving rituximab have evolved.

The American Association for the Study of Liver Disease (AASLD) first mentioned the risk of rituximab related $\mathrm{HBr}$ in their 2007 guidelines. ${ }^{7}$ Routine prophylaxis was recommended in patients with $\mathrm{HBsAg}+$ but not in patients with $\mathrm{HBsAg}-/$ anti-HBc+. ${ }^{7}$ Similarly, in 2009, the European Association for the Study of the Liver (EASL) recommended screening for hepatitis B and recommended preventive NA therapy in patients with chronic hepatitis B virus (HBV) ( $\mathrm{HBsAg}+$ / anti-HBc+) till 12 months after cessation of rituximab. ${ }^{8}$ In contrast, the American Society of Clinical Oncology (ASCO) published a 
Provisional Clinical Opinion in 2010 regarding the CDC's 2008 recommendations. ${ }^{9}$ In ASCO's opinion, there was insufficient evidence supporting the CDC recommendations to screen the general population for HBV prior to initiating therapy with rituximab and felt that the consequences of screening and its economic implications had not been fully considered. ${ }^{9}$ Instead, ASCO recommended screening based on clinical judgement and estimated risk of $\mathrm{HBV} .^{9} \mathrm{~A}$ discretionary recommendation was issued to use NA prophylaxis in patients with chronic HBV since there was a dearth of evidence to support it. ${ }^{9}$ In 2015, the American Gastroenterological Association highlighted the increased risk of $\mathrm{HBr}$, not only in patients who were HBsAg+ but HBsAg-/anti-HBc+, and recommended NA prophylaxis in both of the above populations while receiving rituximab therapy. ${ }^{2}$ This was followed by an updated opinion by ASCO in 2015, that recommended universal screening for HBV receiving immunosuppressive therapies and recommended the use of prophylactic NA therapy. ${ }^{10}$

Management of patients with $\mathrm{HBsAg}-/$ anti-HBc+ has been ambiguous. In 2012, EASL was one of the first associations to detail the management for patients with HBsAg-/anti-HBc+ ${ }^{11}$ EASL recommended NA therapy in $\mathrm{HBsAg}-/$ anti-HBc+ with positive HBV DNA and recommended considering NAs in $\mathrm{HBsAg}-/$ anti-HBc+ and $\mathrm{HBV}$ DNA negative if close monitoring was not assured. ${ }^{11}$ The AASLD guideline updates in 2009 and 2015 did not address NA prophylaxis in patients with $\mathrm{HBsAg}-/$ anti-HBc+ receiving immunosuppressive medications. ${ }^{1}{ }^{12}$

In 2017 and 2018, EASL and AASLD, respectively, published updates on their guidelines regarding HBV and both recommend universal screening with HBsAg and anti-HBc prior to initiating chemotherapy. ${ }^{413}$ Moreover, it is recommended to use NA, preferentially entecavir and tenofovir, for prophylaxis prior to rituximab therapies and continued for 12-18 months after discontinuation of rituximab. ${ }^{413}$ Figure 1 demonstrates a timeline for screening recommendations pertaining to rituximab.

Many centres have reported disappointing adherence, of $20 \%-50 \%$, in screening for HBr susceptibility. ${ }^{514}{ }^{15}$ In this study, we look at the adherence to guidelines and report temporal trends of screening, post-screening interventions and outcomes at a tertiary care hospital.

\section{METHODS}

Patients who received rituximab from January 2005 to December 2017 at a tertiary care centre were included in this retrospective, observational study. Patients were included if they had received at least one dose of rituximab at age 18 or above. The pharmacy database was used to identify consecutive patients that received rituximab in the study time frame.

Data collected included demographics, duration of rituximab therapy, indications and prescriber specialty

\section{Evolution of Recommendations Related to HBV Screening and Nucleoside Analog Prophylaxis in Patients Receiving Rituximab.}

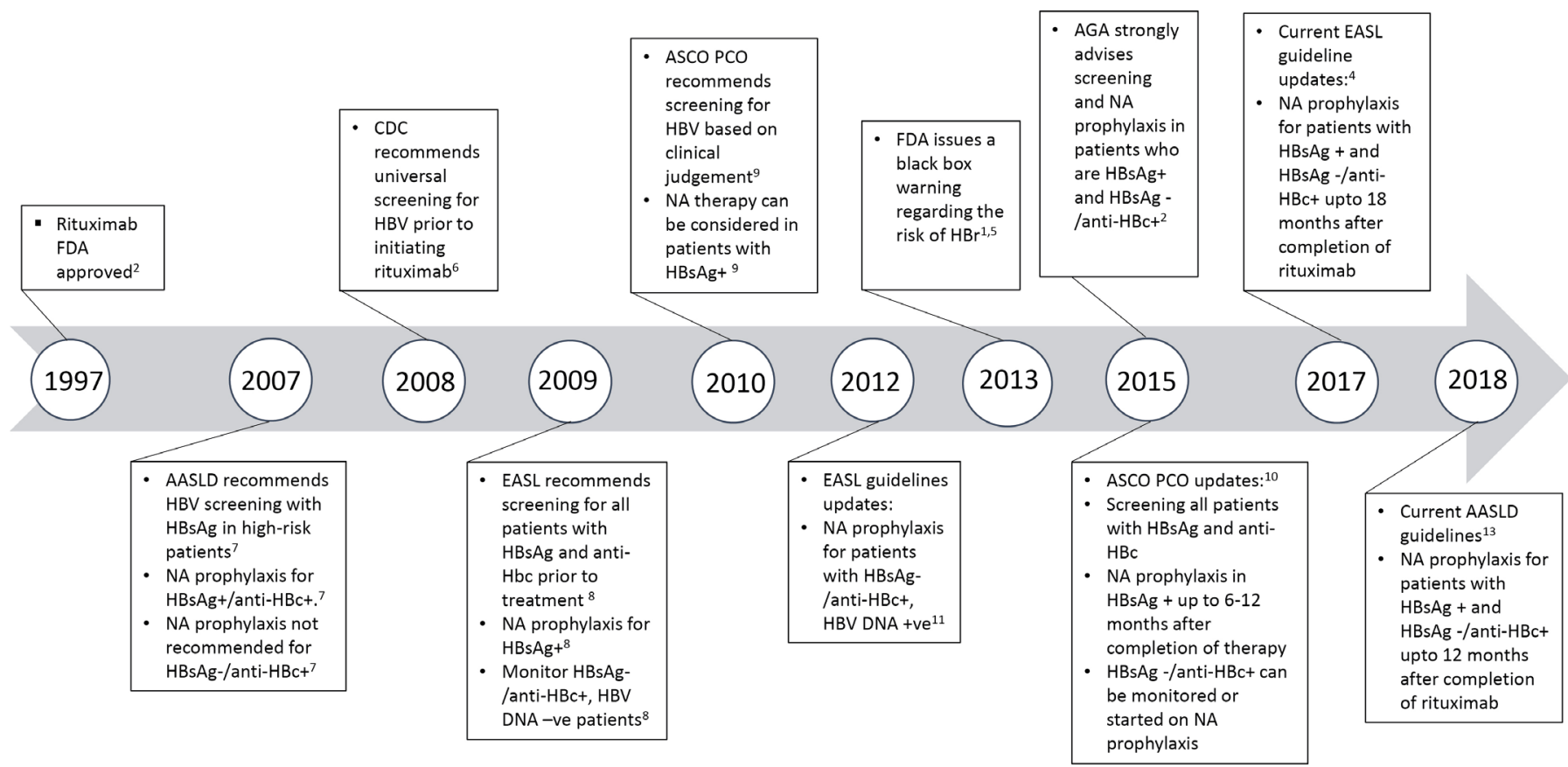

Figure 1 Timeline of screening recommendations pertaining to rituximab. AASLD, American association of the study of liver disease; AGA, American gastroenterological association; anti-HBc, hepatitis B core antibody; ASCO, American society of clinical oncology; CDC, center for disease control and prevention; EASL, European association for the study of the liver; FDA, federal drug administration; $\mathrm{HBr}$, hepatitis B reactivation; HBsAg, hepatitis B surface antigen; HBV, hepatitis B virus; NA, nucleoside analogue; PCO, provisional clinical opinion. 
for rituximab. Date and results of hepatitis B testing were recorded. Testing for hepatitis B included viral serologies: $\mathrm{HBsAg}$, anti-HBc and hepatitis B surface antibody (anti-HBs). Medical records were individually reviewed to confirm testing for hepatitis B. Post-screening actions were recorded as none or use of a NA. Outcomes of screening recorded were change in HBsAg status and change in HBV DNA levels. Outcomes of $\mathrm{HBr}$ were death, persistence (continued HBsAg or HBV DNA positivity) or resolution (loss of HBsAg positivity).

$\mathrm{HBr}$ was defined as HBsAg reverse seroconversion and/ or change in HBV DNA: positive; $\geq 2 \log 10$ increase or $\geq 100000 \mathrm{IU} / \mathrm{mL} .{ }^{3}$ Preventive NA therapy was a prescription of a NA, in a patient at risk of $\mathrm{HBr}$, prior to $\mathrm{HBr}$. Patients with anti-HBc with or without HBsAg were considered at risk of $\mathrm{HBr}$ and considered eligible to receive NA prior to starting and post completion of rituximab therapy. The above definitions were adopted from the standardised nomenclature proposed at a conference on 'Reactivation of Hepatitis B', in 2013, organised by the AASLD. ${ }^{3}$

Cochran-Armitage trend tests were used to assess trends across the years. Analysis was done using SAS. A $\mathrm{p}<0.05$ was considered statistically significant. Data are presented as mean $\pm \mathrm{SD}$, median (25th, 75 th percentiles) or frequency $(\%)$.

\section{Patient and public involvement}

This was a retrospective, chart review study therefore no direct patient involvement was required. There was no public involvement.

\section{RESULTS}

\section{Patient characteristics}

We identified 2219 patients who received rituximab from 2005 to 2017. Fifty-six per cent were men, 84.6\% Caucasian and the average age at starting therapy was $58 \pm 16$ years. The most common prescribing specialty was oncology-haematology $(70.8 \%)$ for the treatment of a lymphoma/leukaemia (63.8\%). The median duration of rituximab therapy was $107(21,562)$ days and the median days from anti-HBc testing to receiving rituximab was 17 $(3,361)$ days.

\section{Group A: patients screened prior to rituximab with at least anti-HBc}

Sixteen hundred and sixty-three patients were tested for hepatitis B prior to starting rituximab. Out of these, $1584(95 \%)$ were tested for anti-HBc. Figure 2 depicts screening results for patients screened prior to rituximab. Figure 3A illustrates the trends of anti-HBc testing, prior to receiving rituximab over the study period.

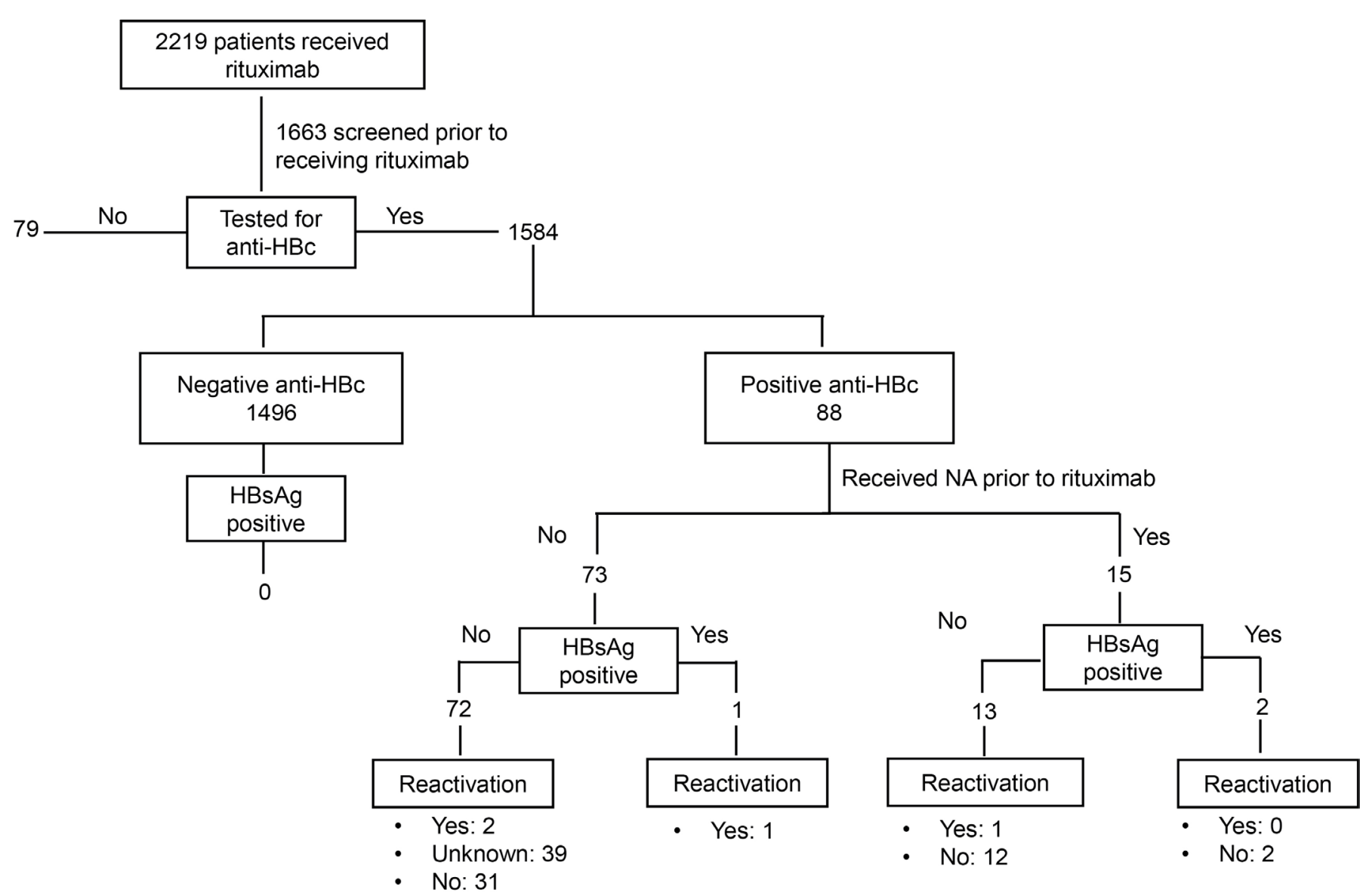

Figure 2 Screening results in patients tested for hepatitis B prior to starting rituximab. Anti-HBc, hepatitis B core antibody; HBsAg, hepatitis B surface antigen; NA, nucleoside analogue. 


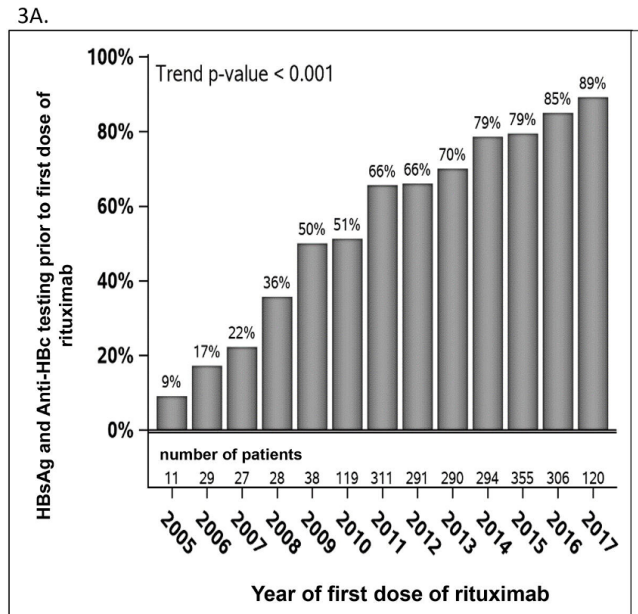

3B.

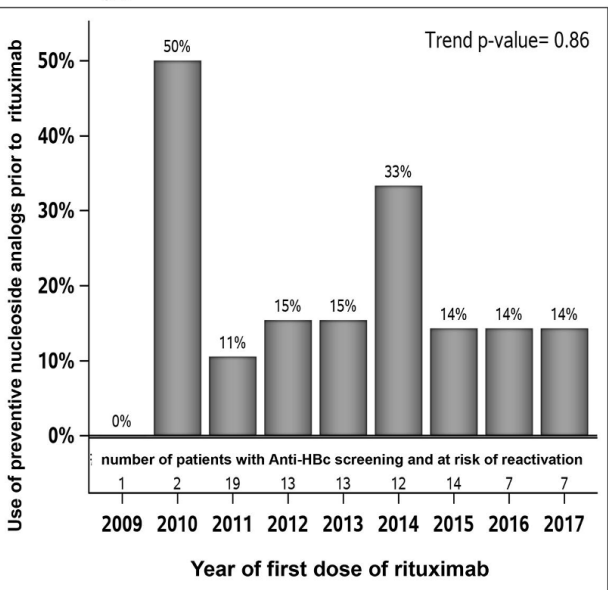

Figure 3 Trends in screening prior to receiving rituximab. (A) Trends of anti-HBc testing prior to the first dose of rituximab. (B) Trends of preventive nucleoside analogue use in patients at risk of hepatitis $B$ reactivation prior to the start of rituximab therapy. Anti-HBc, hepatitis B core antibody; HBsAg, hepatitis B surface antigen.

\section{Group B: patients screened after receiving rituximab with at} least anti-HBc

Figure 4 depicts screening results of patients screened for hepatitis B after receiving rituximab. In the patients that tested negative for anti-HBc, $97 \%$ tested negative for HBsAg and 3\% were not tested for HBsAg. In the group, not tested for anti-HBc, $74 \%$ were not tested for HBsAg either and 26\% tested negative for HBsAg. Two patients in group B were started on preventive NA therapy after screening.
Table 1 shows a comparison between group $\mathrm{A}$ and group B.

\section{Post-screening actions}

In total, $4.5 \%$ patients were positively identified as at risk of $\mathrm{HBr}$. Three patients tested positive for HBsAg and anti-HBc and the remaining were $\mathrm{HbsAg}-/ \mathrm{anti}-\mathrm{HBc}+$. Twenty-three (23\%) of patients at risk of $\mathrm{HBr}$ were prescribed a preventive NA: 15 prior to starting rituximab; and 8 after at least one dose of rituximab. The median days from NA start to

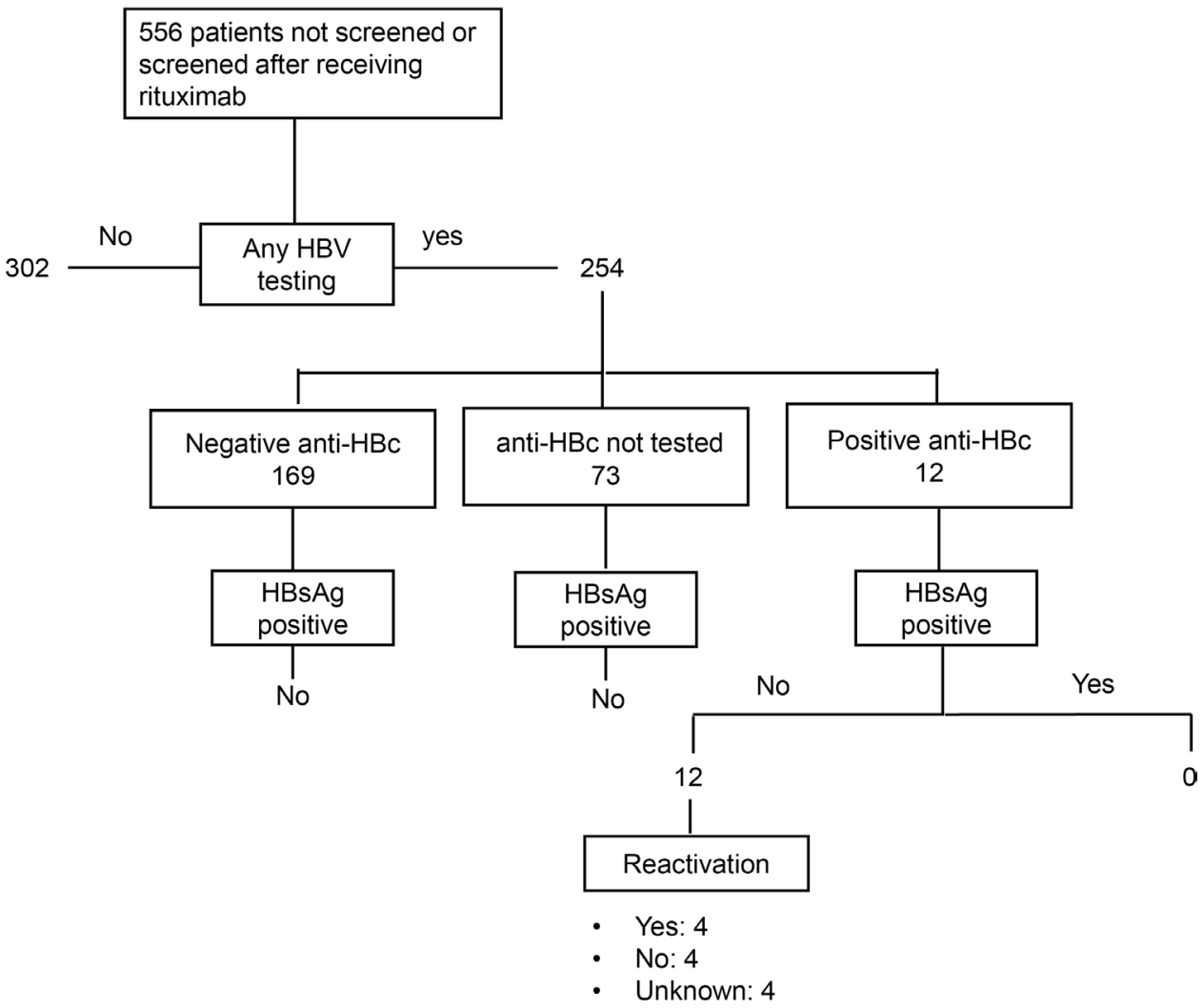

Figure 4 Screening results in patients tested for hepatitis B after starting rituximab. Anti-HBc, hepatitis B core antibody; HBsAg, hepatitis B surface antigen; HBV, hepatitis B virus. 
Table 1 Comparison between group A and group B

\begin{tabular}{|c|c|c|c|}
\hline Characteristic & Group A, n (\%) & Group B, n (\%) & $P$ value \\
\hline & $N=1584$ & $N=181$ & \\
\hline Gender & & & $0.75 \ddagger$ \\
\hline Male & $895(56.5)$ & $100(55.2)$ & \\
\hline Ethnicity & & & $0.65 \ddagger$ \\
\hline Caucasian & $1326(83.7)$ & $148(81.8)$ & \\
\hline African-American & $174(11.0)$ & $26(14.4)$ & \\
\hline Asian & $12(0.76)$ & $1(0.55)$ & \\
\hline Hispanic or Latino & $30(1.9)$ & $2(1.1)$ & \\
\hline Other/unknown & $42(2.7)$ & $4(2.2)$ & \\
\hline Age at first dose of rituximab (years) & $57.5 \pm 15.7$ & $55.5 \pm 14.6$ & $0.11^{*}$ \\
\hline Provider specialty & & & $<0.001 \ddagger$ \\
\hline Oncology-Haematology & $1072(67.7)$ & $120(66.3)$ & \\
\hline Rheumatology & 268 (16.9) & $49(27.1)$ & \\
\hline Transplant & $150(9.5)$ & $3(1.7)$ & \\
\hline Other & $94(5.9)$ & $9(5.0)$ & \\
\hline Indication for rituximab & & & $<0.001 \neq$ \\
\hline Lymphoma/leukaemia & $974(61.5)$ & $106(58.6)$ & \\
\hline Autoimmune disease & $178(11.2)$ & $24(13.3)$ & \\
\hline Glomerulonephritis & $22(1.4)$ & $0(0.0)$ & \\
\hline Vasculitis & $191(12.1)$ & $38(21.0)$ & \\
\hline Other & $219(13.8)$ & $13(7.2)$ & \\
\hline Days from screening to first dose of rituximab & $25(6,494)$ & $-442(-1367,-26)$ & $<0.001 \dagger$ \\
\hline At risk of $\mathrm{HBr}$ & $88(5.6)$ & $12(6.6)$ & $0.55 \ddagger$ \\
\hline \multirow[t]{2}{*}{ Use of prophylactic NA } & $21(1.3)$ & $2(1.1)$ & $0.99 \S$ \\
\hline & $N=88$ & $\mathrm{~N}=12$ & \\
\hline \multirow[t]{2}{*}{ Reactivation status in anti-HBc positive } & $4(4.5)$ & $4(33.3)$ & $0.003 \ddagger$ \\
\hline & $\mathrm{N}=24$ & $N=6$ & \\
\hline \multirow[t]{2}{*}{ Preventive NA use in those that received an NA } & $21(87.5)$ & $2(33)$ & $0.005 \S$ \\
\hline & $\mathrm{N}=4$ & $\mathrm{~N}=4$ & \\
\hline Outcomes of $\mathrm{HBr}$ & & & $0.99 \dagger$ \\
\hline Death & $2(50.0)$ & $1(25.0)$ & \\
\hline Persistence & $2(50.0)$ & $2(50.0)$ & \\
\hline Resolved & $0(0.0)$ & $1(25.0)$ & \\
\hline
\end{tabular}

Statistics presented as mean \pm SD, median $(\mathrm{P} 25, \mathrm{P} 75)$ or $\mathrm{N}$ (column \%).

*ANOVA.

†Kruskal-Wallis test.

$\ddagger$ Pearson's $\chi^{2}$ test.

$\S$ Fisher's exact test.

Anti-HBc, hepatitis B core antibody; HBr, hepatitis B reactivation; NA, nucleoside analogue; ULN, upper limit of normal.

rituximab was $4(0,32)$ and the median duration of use was $306.5(174,733)$ days. Entecavir $(70 \%)$ was the most commonly prescribed NA. Figure 3B illustrates the trends of preventive NA use in patients at risk of $\mathrm{HBr}$ prior to the start of rituximab therapy.

\section{Reactivation}

$\mathrm{HBr}$ was identified in $0.4 \%$ of those receiving rituximab ( $8 \%$ of those at risk). Reactivation occurred in one
(12.5\%) patient who was $\mathrm{HBsAg}+/ \mathrm{anti}-\mathrm{HBc}+$ and in 7 $(87.5 \%)$ who were $\mathrm{HBsAg}-/$ anti-HBc+. In those that reactivated, $87.5 \%$ were not prescribed preventive NA. Of those at risk and given NA prophylaxis, 96\% remained free of $\mathrm{HBr}$. One case of $\mathrm{HBr}$ occurred in a patient prescribed a preventive NA prior to starting rituximab. Reactivation was identified 1503 days after the last dose of rituximab when he presented with relapsed chronic lymphocytic 


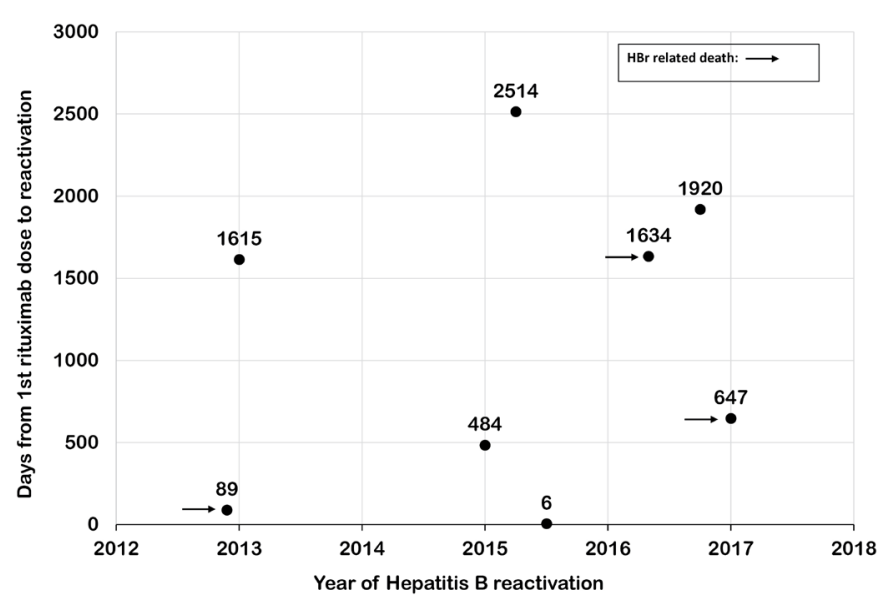

Figure 5 Days from first dose of rituximab to reactivation and hepatitis $\mathrm{B}$ related mortality. $\mathrm{HBr}$, hepatitis $\mathrm{B}$ reactivation.

leukaemia after being lost to follow for several years. The status of $\mathrm{HBr}$ was unknown in 49 patients as repeat serologic testing was unavailable. Repeat testing, either HBV DNA levels and/or HBsAg serology, was done in 43 patients and no reactivation was identified.

All patients at risk and not prescribed NA prophylaxis tested negative for $\mathrm{HBsAg}$ and were either anti-HBc+/ anti-HBs+ or anti-HBc+/anti-HBs-. Of these, $9 \%$ had $\mathrm{HBr}$, status of $\mathrm{HBr}$ was unknown in $49 \%$ and repeat serologic testing in $42 \%$ was negative.

While $\mathrm{HBr}$ was rare, it was fatal in three $(37.5 \%)$, persistent in four $(50 \%)$ and resolved in one $(12.5 \%)$. The median time from starting rituximab to identification of reactivation was $1131(286,1777)$ days. The median time from the last dose of rituximab to identification of $\mathrm{HBr}$ was $59(-66,812)$ days. $\mathrm{HBr}$ was identified greater than 18 months after the last dose of rituximab in two patients. Two patients continued to receive rituximab even after reactivation and were started on a NA; the infection persisted in these patients. The median duration of rituximab in those who reactivated was 342 (34, 1249) days. The three fatalities from $\mathrm{HBr}$ occurred in patients that were $\mathrm{HBsAg}-/$ anti-HBc+ on initial screening. Figure 5 illustrates, in a graph, the time-to-reactivation from the first dose of rituximab. The rate of $\mathrm{HBr}$ in the intervals 2005-2008, 2009-2014 and 2013-2017 was 0\%, 0.26\% and $0.44 \%$, respectively.

\section{DISCUSSION}

Our study describes the real-life practices and outcomes of hepatitis B screening in patients receiving rituximab for oncologic and non-oncologic conditions over a 13-year period. We found evolution of near-universal hepatitis B screening; a rate much higher than other reported series. ${ }^{516}$ Testing for anti-HBc and HBsAg increased from $9 \%$ to $87 \%$ from 2005 to 2017 . The rate of increase in screening was highest 2008-2014 which correlates with recommendations and awareness of $\mathrm{HBr}$. During this time period, at our institute, no automatic clinical reminder had been implemented and the steady rise in screening rates was a consequence of prescriber awareness and adherence to guidelines and warnings issued.

Comparison of group A and group B revealed no statistically significant difference in the prevalence of patients at risk of $\mathrm{HBr}$. In group $\mathrm{A}, 5.6 \%$ were at risk of $\mathrm{HBr}$ and in group $\mathrm{B} 6.6 \%, \mathrm{p}=0.55$. However, the incidence of $\mathrm{HBr}$ was higher in group B versus group A $(33.3 \%$ vs $4.5 \%$, $\mathrm{p}=0.003)$. Conversely, the proportion of preventive NA use was lower in group B (33\%) compared with group A $(87.5 \%), \mathrm{p}=0.005$. Of note, $87.5 \%$ of $\mathrm{HBr}$ was in patients not prescribed a preventive NA. These findings illustrate that timely screening and use of preventive NA was associated with a decrease in the incidence of $\mathrm{HBr}$, in our cohort.

While the rate of screening has become nearly universal, only $23 \%$ of at-risk patients received guideline recommended preventive therapy. No temporal trend was seen in the prescription of preventive NA therapy and it did not mirror hepatitis B screening trends. Moreover, the rate of $\mathrm{HBr}$ increased over time even though screening improved. Recommendations pertaining to NA prophylaxis have been evolving through this time period whereas screening recommendations remained consistent and robust. This may explain the discrepancy between screening and preventive NA trends. In our cohort, the majority (98\%) of the patients at risk were $\mathrm{HBsAg}-/$ anti-HBc+ and it is only in the last few years that guidelines have strongly recommended preventive NAs for patients that test $\mathrm{HBsAg}-/$ anti-HBc+. ${ }^{413}$

Figure 1 highlights the frequent amendments and variations to the guidelines. This must have posed a challenge, for practitioners, to follow and remain updated. For instance, in 2010, ASCO's recommendations differed from other guidelines as they did not strongly endorse universal screening or NA prophylaxis. ${ }^{9}$ It was not until 2015 that their opinion changed. ${ }^{10}$ In our cohort, the majority indications for rituximab were oncologic however it is undiscernible if ASCO's opinion influenced practice or not.

Current guidelines recommend $\mathrm{HBsAg}$ and anti-HBc testing prior to administering rituximab. ${ }^{413}$ We found that all patients, identified as at risk for $\mathrm{HBr}$, were positive for anti-HBc. Furthermore, our cohort reflects a low prevalence of hepatitis B, evidenced by the presence of past hepatitis B at around $5 \%$ and chronic hepatitis less than $1 \% .^{13}$ Therefore, the incidence of acute hepatitis B ( $\mathrm{HBsAg}+/$ anti-HBc and anti-HBs-) would be very low and in retrospect testing with only anti-HBc would have identified all at-risk patients. It is plausible, that in low prevalence populations, anti-HBc may be sufficient and the most pertinent test required to identify at-risk patients.

Figure 5 illustrates the wide range of days from the first dose of rituximab to reactivation. In our study, $\mathrm{HBr}$ was identified as early as 6 days and as late as 6 years from the first dose of rituximab. In the patient, in whom reactivation occurred several years after completion of rituximab was diagnosed with a new malignancy at the time of the $\mathrm{HBr}$ and hence $\mathrm{HBr}$ 
may not be directly related to previous rituximab therapy. However, similar variability was reported, in a study of patients with Non-Hodgkin's lymphoma, in which $\mathrm{HBr}$ occurred at 2.7 to 213 weeks after the last cycle of rituximab. ${ }^{17}$ This may be explained by the fact that $\mathrm{HBr}$ was only identified if repeat $\mathrm{HBV}$ testing was performed and therefore, reactivation may have occurred earlier but not detected. On the other hand, a lack of clinical hepatitis may have deterred repeated testing for viral hepatitis. In our cohort, $\mathrm{HBr}$ mortality was high and occurred in patients, identified with $\mathrm{HBr}$, months after the first dose of rituximab. It is pertinent to note that all cases of $\mathrm{HBr}$ were identified after 2013, the year that the FDA issued a black box warning regarding $\mathrm{HBr}$. In our patients, the majority that reactivated were $\mathrm{HBsAg}-/$ anti-HBc+ and the risk of $\mathrm{HBr}$ must have been thought to be low. Moreover, with increasing awareness more patients were identified.

The appropriate duration of preventive NA post rituximab is unclear. Current guidelines recommend NA use for 12-18 months (180-540 days) post rituximab followed by surveillance for 1 year. ${ }^{43}$ Our data shows that two (25\%) developed reactivation more than 540 days after end of treatment. The cost-benefit of continued NA versus surveillance is a suitable topic for further investigation.

The limitations of this study were its retrospective and observational study design which did not allow for an assessment into the reasons for non-adherence to guidelines and likely underestimated the incidence of $\mathrm{HBr}$. It is possible that not all cases of $\mathrm{HBr}$ were identified as repeat testing for hepatitis B was required to diagnose $\mathrm{HBr}$ and was not routinely conducted in patients at risk.

In conclusion, our study demonstrates near-universal adherence to screening recommendations for hepatitis B prior to rituximab can be achieved. However, screening unlinked to preventive NA use in those who are anti-HBc+, is ineffective in reducing $\mathrm{HBr}$. Use of NA is $96 \%$ protective against $\mathrm{HBr}$. Renewed efforts are needed to assure NA treatment is used in patients with anti-HBc+ receiving rituximab. The risk of $\mathrm{HBr}$ may be present for a prolonged period of time after the discontinuation of rituximab. More studies are needed to evaluate the risk of $\mathrm{HBr}$, after the discontinuation of rituximab, to risk stratify patients and verify current management strategies.

Contributors MH contributed to study concept and design, acquisition of data, drafting of the manuscripts and interpretation of data. GF contributed to acquisition of data. RL contributed to statistical analysis. WC contributed to study concept and design, interpretation of data, critical revision of the manuscript for important intellectual content and study supervision.

Funding The authors have not declared a specific grant for this research from any funding agency in the public, commercial or not-for-profit sectors.

Competing interests None declared.

Patient and public involvement Patients and/or the public were not involved in the design, or conduct, or reporting, or dissemination plans of this research.
Patient consent for publication Not required.

Ethics approval This study was approved by the Institutional Review Board at the Cleveland Clinic.

Provenance and peer review Not commissioned; externally peer reviewed.

Data availability statement All data relevant to the study are included in the article or uploaded as supplementary information. All data relevant to the study are included in the article.

Open access This is an open access article distributed in accordance with the Creative Commons Attribution Non Commercial (CC BY-NC 4.0) license, which permits others to distribute, remix, adapt, build upon this work non-commercially, and license their derivative works on different terms, provided the original work is properly cited, appropriate credit is given, any changes made indicated, and the use is non-commercial. See: http://creativecommons.org/licenses/by-nc/4.0/.

ORCID iD

Mahnur Haider http://orcid.org/0000-0002-9095-2499

\section{REFERENCES}

1 Hwang JP, Barbo AG, Perrillo RP. Hepatitis B reactivation during cancer chemotherapy: an international survey of the membership of the American association for the study of liver diseases. $J$ Viral Hepat 2015;22:346-52.

2 Perrillo RP, Gish R, Falck-Ytter YT. American gastroenterological association Institute technical review on prevention and treatment of hepatitis $B$ virus reactivation during immunosuppressive drug therapy. Gastroenterology 2015;148:221-44.

3 Hwang JP, Lok AS-F. Management of patients with hepatitis B who require immunosuppressive therapy. Nat Rev Gastroenterol Hepatol 2014;11:209-19.

4 Lampertico P, Agarwal K, Berg T. EASL 2017 clinical practice guidelines on the management of hepatitis $B$ virus infection. $J$ Hepatol 2017;62:336A.

5 Leonard AN, Love BL, Norris LB, et al. Screening for viral hepatitis prior to rituximab chemotherapy. Ann Hematol 2016;95:27-33.

6 Weinbaum CM, Williams I, Mast EE, et al. Recommendations for Identification and Public Health Management of Persons with Chronic Hepatitis B Virus Infection. Centers for Disease Control and Prevention. Published September 19, 2008. Available: https://www. cdc.gov/mmwr/preview/mmwrhtml/rr5708a1.htm

7 Lok ASF, McMahon BJ. Chronic hepatitis B. Hepatology 2007:45:507-39.

8 European Association For The Study Of The Liver. EASL clinical practice guidelines: management of chronic hepatitis B. $J$ Hepatol 2009;50:227-42.

9 Zon RT, Neuss MN. ASCO provisional clinical opinion: chronic hepatitis B virus infection in patients receiving cytotoxic chemotherapy for treatment of malignant diseases. $J$ Oncol Pract 2010;6:193-4.

10 Hwang JP, Artz AS, Somerfield MR. Hepatitis B virus screening for patients with cancer before therapy: American Society of clinical oncology provisional clinical opinion update. $J$ Oncol Pract 2015;11:e487-9.

11 European Association For The Study Of The Liver. EASL clinical practice guidelines: management of chronic hepatitis $B$ virus infection. J Hepatol 2012;57:167-85.

12 Lok ASF, McMahon BJ. Chronic hepatitis B: update 2009. Hepatology 2009;50:661-2.

13 Terrault NA, Lok ASF, McMahon BJ, et al. Update on prevention, diagnosis, and treatment of chronic hepatitis B: AASLD 2018 hepatitis B guidance. Hepatology 2018;67:1560-99.

14 Hunt CM, Beste LA, Lowy E, et al. Veterans health administration hepatitis $B$ testing and treatment with anti-CD20 antibody administration. World J Gastroenterol 2016;22:4732-40.

15 Hwang JP, Fisch MJ, Zhang $\mathrm{H}$, et al. Low rates of hepatitis B virus screening at the onset of chemotherapy. J Oncol Pract 2012;8:e32-9.

16 Liu CY, Chandrasekar PH, Masood A, et al. Adherence to hepatitis $B$ screening and prophylactic lamivudine for prevention of rituximab-associated hepatitis B reactivation. $J$ Oncol Pharm Pract 2013;19:18-23.

17 Hsiao L-T, Chiou T-J, Gau J-P, et al. Risk of reverse seroconversion of hepatitis $B$ virus surface antigen in Rituximab-Treated non-Hodgkin lymphoma patients: a large cohort retrospective study. Medicine 2015;94:e1321. 